\title{
Diatomáceas (Bacillariophyceae) epífitas em Acrostichum danaeifolium (Pteridaceae) no Arroio Pseudônimo, Pelotas, Rio Grande do Sul, Brasil
}

\author{
Vanessa Correa da $\operatorname{Rosa}^{1^{*}} \&$ Marinês Garcia ${ }^{2}$ \\ ${ }^{1}$ Programa de Pós-Graduação em Biologia de Ambientes Aquáticos Continentais, Universidade Federal do Rio \\ Grande, Rio Grande do Sul, Brasil. \\ ${ }^{2}$ Departamento de Botânica, Universidade Federal de Pelotas, Rio Grande do Sul, Brasil.
}

\begin{abstract}
Resumo - Considerando o conhecimento científico insuficiente de diatomáceas associadas a plantas em áreas úmidas, este estudo teve como objetivo apresentar a composição florística de diatomáceas epífitas no Arroio Pseudônimo e imagens das espécies que representam o primeiro registro para o estado do Rio Grande do Sul. Foram coletadas 12 amostras de frondes da samambaia Acrostichum danaeifolium ao longo de quatro estações do ano (maio de 2011 a janeiro de 2012). Acrostichum danaeifolium apresenta distribuição limitada no Arroio Pseudônimo (Lagoa Pequena), Pelotas. Foram medidas as variáveis físicas (temperatura, profundidade, transparência da água e vazão) e químicas ( $\mathrm{pH}$, condutividade elétrica, fósforo e nitrogênio) da água. O material epifítico foi removido e foram preparadas lâminas permanentes para a observação e identificação dos taxons. A flora de diatomáceas mostrou alta riqueza (157 espécies); Nitzschia apresentou o maior número de táxons (22). A comunidade foi formada por táxons de água doce (26\%), estuarinos (50\%) e marinhos (14\%), das classes Bacillariophyceae (75\%), Coscinodiscophyceae (17\%) e Fragillariophyceae (8\%). Os maiores valores de riqueza ocorreram no verão (99 espécies) e no outono (90), comparadas à primavera (46) e inverno (29). Vinte e três espécies são registradas pela primeira vez para o Rio Grande do Sul.
\end{abstract}

Palavras-chave adicionais: áreas úmidas, diversidade, estuários, Lagoa dos Patos, riqueza, região subtropical, taxonomia.

\begin{abstract}
Epiphytic diatoms (Bacillariophyceae) on Acrostichum danaeifolium (Pteridaceae) at Arroio Pseudônimo, Pelotas, Rio Grande do Sul, Brazil) - Considering the insufficient scientific knowledge of diatoms attached to plants in wetlands, this study aims to present their floristic composition in Arroio Pseudônimo and also images of species that represent first records for the State of Rio Grande do Sul, Brazil. Twelve samples from the fern Acrostichum danaeifolium fronds were collected, over four seasons (from May 2011 to January 2012). Acrostichum danaeifolium has a limited distribution in Arroio Pseudônimo (Lagoa Pequena), Pelotas. Epiphytic material was removed and permanent slides were prepared for observation and identification. Physical (temperature, depth, water transparency and flow) and chemical $(\mathrm{pH}$, electrical conductivity, phosphorus and nitrogen) variables of water were measured. The diatom flora showed high species richness (157); Nitzschia displayed the highest number of taxa (22). The community was composed of taxa characteristic of fresh water (26\%), estuarine (50\%) and marine (14\%), from classes Bacillariophyceae (75\%), Coscinodiscophyceae (17\%) and Fragillariophyceae (8\%). The greatest richness occurred in summer (99 species) and autumn (90), compared to spring (46) and winter (29). Twenty-three species are recorded for the first time to Rio Grande do Sul.
\end{abstract}

Additional key words: diversity, estuary, Lagoa dos Patos, subtropical region, richness, taxonomy, wetlands.

O conhecimento científico insuficiente sobre a riqueza de espécies em áreas úmidas e sua rápida degradação tornam urgente a realização de estudos para auxiliar na conservação destes ambientes de alta biodiversidade (Maltchik et al. 2010). A Lagoa Pequena, Rio Grande do Sul, é uma área referida pela Base de Dados Tropicais (2003) como prioritária para a conservação, visto que apresenta lagoas e banhados bem preservados, aves aquáticas de interesse para a conservação, e é um criadouro natural de peixes como a tainha e a traíra (Alves et al. 2009).

Além da escassez de inventários de flora e fauna em áreas úmidas no Brasil, também existe pouca informação sobre as diatomáceas associadas a plantas em áreas costeiras. A grande maioria dos estudos de diatomáceas epífitas aborda as macroalgas e a vegetação rasteira (gramíneas e ciperáceas em geral)

\footnotetext{
*Autora para correspondência: vanessacorrea3@gmail.com

Editor responsável: Alessandro Rapini

Submetido: 9 out. 2012; aceito: 26 mar. 2013

Publicação inicial: 26 jul. 2013; versão final: 2 maio 2014
}

(Chen et al. 2010). Na Região Sul, foram registrados 106 táxons de diatomáceas epífitas na macrófita' aquática Polygonum hydropiperoides Michaux, das quais, nove espécies cêntricas e 97 penadas, sendo Navicula Bory, Gomphonema Ehrenberg e Nitzschia Hassal. os gêneros com maior número de espécies (Bertolli et al. 2010). Por outro lado, Santos et al. (2011) encontraram 147 táxons (somente três espécies cêntricas, as demais penadas) associados à macrófita Potamogeton polygonus Cham. \& Schltdl, onde Eunotia Ehrenberg e Pinnularia Ehrenberg apresentaram o maior número de espécies. No estado do Rio Grande do Sul, os estudos de algas epifíticas envolveram somente partes de macrófitas aquáticas coletadas através da técnica de espremido manual (Flôres et al. 1999; Ludwig et al. 2004), não havendo estudos de diatomáceas epífitas sobre plantas específicas.

O gênero de samambaia Acrostichum (Pteridaceae) apresenta distribuição pantropical, incluindo pelo menos três espécies (Tryon \& Tryon 1982; Marcon 2000): A. speciosum Willd (paleotropical), A. aureum 
L. (pantropical) e A. danaeifolium Langst. \& Fisch. (neotropical). No Brasil, ocorrem $A$. aureum e A. danaeifolium. Acrostichum danaeifolium apresenta distribuição mais ampla que $A$. aureum, podendo ocorrer juntamente com ela ou em locais alagados mais afastados da costa litorânea (Marcon 2000). É registrada para os estados de Pernambuco, Rio de Janeiro, Paraná, São Paulo, Santa Catarina, Rio Grande do Sul (banhado de Tramandaí), e, na Paraíba, ocorre em um remanescente de floresta Atlântica (Sehnem 1972; Farias \& Xavier 2011).

As diatomáceas epífitas servem de alimento para muitos organismos aquáticos, como peixes, insetos e fauna bentônica (Moschini-Carlos 1999). Estas microalgas podem formar agregados de massas visíveis sobre o caule, folhas e raízes de macrófitas aquáticas, como comumente observado em um arroio próximo à cidade de Pelotas, no sul do Brasil, o Arroio Pseudônimo. O objetivo deste trabalho é apresentar a composição florística de diatomáceas epífitas em $A$. danaeifolium em diferentes períodos de coleta no Arroio Pseudônimo, bem como imagens das espécies registradas pela primeira vez no Rio Grande do Sul.

\section{MATERIAL E MÉtodos}

Área de estudo. O Arroio Pseudônimo (31 $\left.{ }^{\circ} 40^{\prime} 16.4^{\prime \prime S}, 52^{\circ} 04^{\prime} 51.4^{\prime \prime} \mathrm{W}\right)$ está localizado na Lagoa Pequena, uma área úmida da Planície Costeira do estado do Rio Grande do Sul, situada na parte sudoeste da Lagoa dos Patos, próximo ao limite da região estuarina, na extremidade norte do Saco do Laranjal, entre as coordenadas $31^{\circ} 40^{\prime} 57.93^{\prime \prime} \mathrm{S}, 52^{\circ} 05^{\prime} 10.29^{\prime \prime} \mathrm{W}$ na extremidade sul e $31^{\circ} 33^{\prime} 02.87^{\prime \prime} \mathrm{S}, 52^{\circ} 05^{\prime} 04.17^{\prime \prime} \mathrm{W}$ na extremidade norte. Esta Lagoa inunda terras dos municípios de Pelotas e Turuçu (Figura 1).

O Arroio Pseudônimo apresenta $1,81 \mathrm{~km}$ de extensão e $14 \mathrm{~m}$ de largura, profundidade média de $2 \mathrm{~m}$ na região central e $0,56 \mathrm{~m}$ na margem (obs. pess.). É um ambiente que drena a água das chuvas das áreas alagadas marginais e, dependendo de condições como padrões de vento e precipitação, o fluxo de água pode ocorrer em direção ao estuário da Lagoa dos Patos ou em direção ao sangradouro da Lagoa Pequena, podendo apresentar salinidade elevada, dependendo das condições.

Em períodos de não estiagem e quando o vento é predominante do quadrante nordeste, a água doce oriunda da Lagoa dos Patos entra na Lagoa Pequena através dos arroios Canaleta da Feitoria e Tapado, e flui em direção ao estuário da Lagoa dos Patos pelo Arroio Pseudônimo e entrada do sangradouro. Porém, em períodos de estiagem e vento predominante do quadrante sul, a água salobra do estuário da Lagoa dos Patos entra na Lagoa Pequena através do Arroio Pseudônimo e entrada do sangradouro. A água doce dos arroios Corrientes e Contagem entra na Lagoa
Pequena quando ela apresenta menor nível de água; já em maior nível, a água da Lagoa Pequena entra nesses arroios, conforme observações do ambiente e informações fornecidas por Couto (pescador artesanal da colônia de pescadores Z3). Segundo este padrão, a Lagoa Pequena pode sofrer influências tanto físicas (sedimentos) e químicas (nutrientes) quanto biológicas (espécies estuarinas e marinhas) da região estuarina ou da área límnica da Lagoa dos Patos.

Nas margens do Arroio Pseudônimo crescem macrófitas aquáticas enraizadas, tais como Schoenoplectus californicus (C.A.Mey) Soják, Typha dominguensis Pers., A. danaeifolium, Myriophylum brasiliense Camb., Cabomba caroliniana A.Gray, e macrófitas flutuantes, como Salvinia herzogii de la Sota, Azolla sp. e Pistia stratiotes L. Também ocorrem Hibiscus diversifolius Jacq. e Senecio bonariensis Hook \& Arn. Entretanto, a espécie dominante no Arroio Pseudônimo é a ciperácea Schoenoplectus americanus (Pers.) Volk ex Schinz \& Kell.

Coleta e análise das amostras. Foram coletadas 12 amostras de frondes adultas de $A$. danaeifolium em contato com a água, ao longo das quatro estações do ano (maio, agosto e dezembro de 2011 e janeiro de 2012). Em cada estação, foram amostradas três frondes de um mesmo indivíduo. Três pinas de cada fronde foram fixadas com solução de formalina a $4 \%$. O material aderido nas pinas foi removido com auxílio de pincel $\mathrm{n}^{\mathrm{o}} 10$ e de jatos de água destilada do próprio frasco de origem. $\mathrm{O}$ material removido foi transferido para vidros de $20 \mathrm{ml}$ a fim de padronizar as amostras.

De cada amostra foram retirados $2 \mathrm{ml}$ de subamostra para a preparação de lâminas permanentes, que seguiu o método descrito por Simonsen (1974), com uso da resina Naphrax ${ }^{\circledR}$. Foram analisadas 24 lâminas permanentes, duas por amostra. As lâminas foram examinadas em microscópio óptico Olympus BX 40 para identificação dos táxons. Foram contadas no mínimo 400 valvas de diatomáceas por amostra, através de contagens de aproximadamente 200 valvas por lâmina permanente. A abundância foi calculada levando-se em consideração o número de valvas contadas e o número de espécies identificadas em cada lâmina. Foram consideradas espécies abundantes, aquelas cujo valor obtido foi superior à média calculada para a lâmina. Após a contagem, toda a área das lâminas foi visualizada para a identificação dos demais taxóns presentes. As amostras encontram-se no Herbário HURG da Universidade Federal de Rio Grande.

Foram determinadas as variáveis ambientais $\mathrm{pH}$ (pHmetro Lutron pH-206), condutividade elétrica (condutivímetro Lutron CD-4303), temperatura da água (termômetro Arba), profundidade e transparência da água (disco de Secchi). A vazão foi calculada segundo Carvalho (2008), levando-se em consideração a largura do arroio, a profundidade média e a 


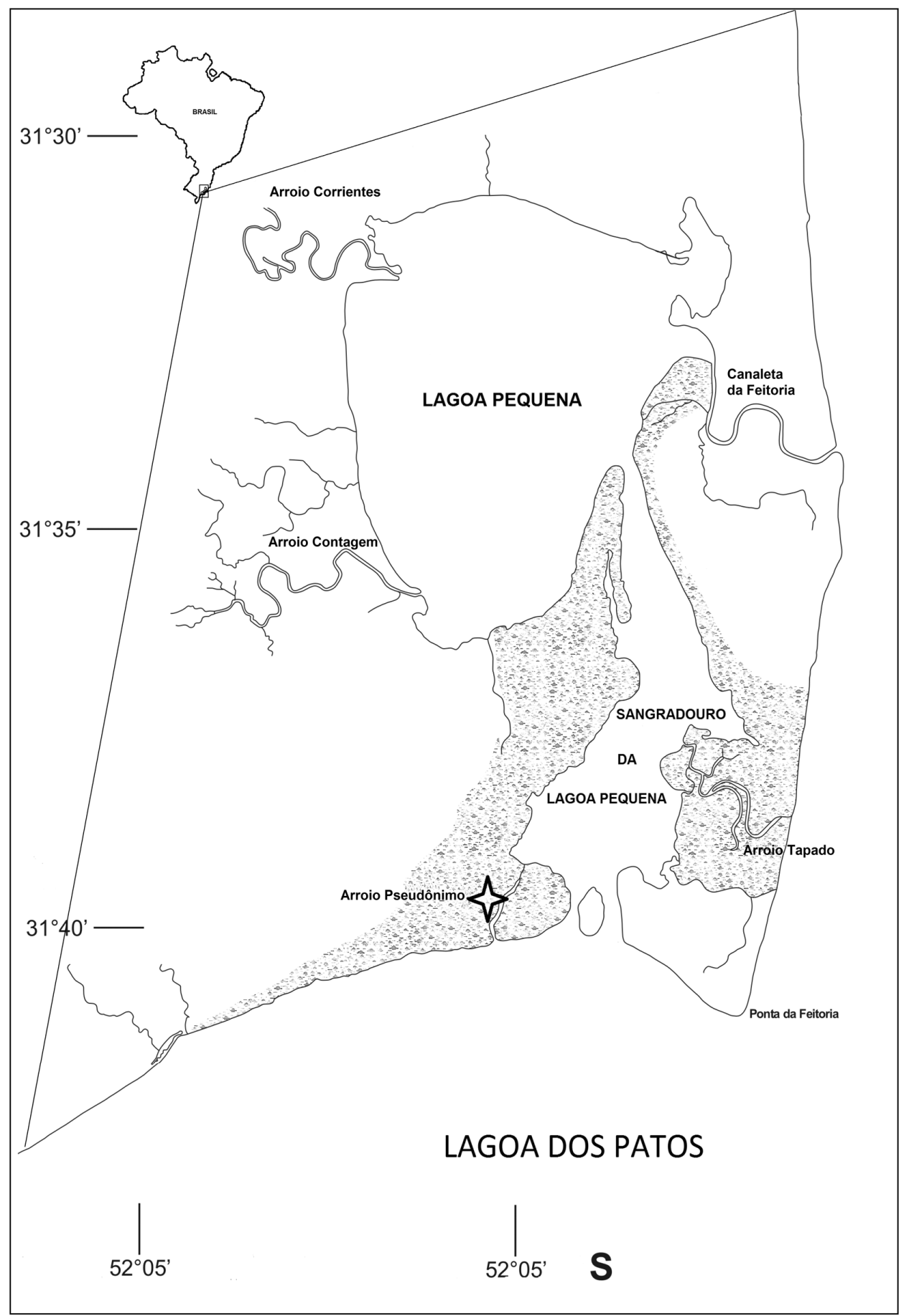

Figura 1. Região da Lagoa Pequena, indicando o Arroio Pseudônimo, junto ao estuário da Lagoa dos Patos, Pelotas, Rio Grande do Sul, Brasil.

velocidade média do fluxo de água. Foram também coletadas amostras de um litro de água para determinação do fósforo total (Valderrama 1981; Baumgarten et al. 1996) e do nitrogênio orgânico total (Mackereth et al. 1978).

A identificação de Acrostichum danaeifolium está baseada em Sehnem (1972). A identificação das diatomáceas está baseada em literatura especializada (e.g., Hustedt 1930; Jensen 1985; Simonsen 1987a,b; Krammer \& Lange-Bertalot 1991a,b; Witkowski 1994; Witkowski et al. 2000; Metzeltin et al. 2005). Para determinar registros de primeira ocorrência, foi realizada consulta ao catálogo de diatomáceas do Rio Grande do Sul (Torgan et al. 1999). As coleções dos herbários HAS, da Fundação Zoobotânica do Rio Grande do Sul, e Bradeanum (PEL), da Universidade Federal de Pelotas, também foram consultadas. As espécies registradas pela primeira vez no Rio Grande do Sul foram ilustradas com imagens obtidas por captura digital no microscópio BX51, sendo fornecidos detalhes métricos e, sempre que possível, dados da distribuição e aspectos ecológicos. 


\section{RESULTADOS}

A macrófita aquática emergente $A$. danaeifolium apresenta uma distribuição restrita no Sul do estado do Rio Grande do Sul (Lagoa Pequena), ocorrendo apenas na porção sudoeste desta grande área úmida, mais especificamente em um fragmento de $500 \mathrm{~m}$ na margem oeste do Arroio Pseudônimo. Este é o registro mais austral da espécie em território brasileiro.

$\mathrm{O} \mathrm{pH}$ no Arroio variou de neutro a alcalino $(7,08 \mathrm{e}$ 8,89 ). A profundidade foi mais baixa na primavera e no verão $(0,35 \mathrm{~m})$ do que no inverno $(0,80)$ e no outono $(0,76)$. A temperatura da água variou entre o mínimo de $10^{\circ} \mathrm{C}$ (inverno), $18^{\circ} \mathrm{C}$ (outono), $26^{\circ} \mathrm{C}$ (primavera) e $24^{\circ} \mathrm{C}$ (verão). A diferença de $2^{\circ} \mathrm{C}$ entre a temperatura da primavera e do verão pode ser justificada pelo fato de que em áreas subtropicais podemos ter, durante o verão, temperatura de $10^{\circ} \mathrm{C}$, semelhante a temperaturas de inverno. A vazão da água foi menor no verão $\left(9,4 \mathrm{~m}^{3} \mathrm{~s}^{-1}\right)$ e primavera $(12,02)$ e maior no inverno $(42,12)$. A transparência da água atingiu toda a sua coluna no outono e verão, $0,23 \mathrm{~m}$ na primavera e 0,20 $\mathrm{m}$ inverno. Os maiores valores de condutividade elétrica foram encontrados no verão $\left(15,83 \mathrm{mS} \mathrm{cm}^{-1}\right) \mathrm{e}$ outono $(3,80)$ e os menores na primavera $(3,43)$ e inverno $(0,65)$. O fósforo total foi maior no outono $\left(0,09 \mathrm{mg} \mathrm{cm}^{-1}\right)$ e primavera $(0,11)$ e menor no inverno $(0,03)$ e verão $(0,04)$. $O$ nitrogênio orgânico total foi maior no inverno $\left(0,44 \mathrm{mg} \mathrm{L}^{-1}\right)$ e primavera $(0,49) \mathrm{e}$ menor no outono $(0,29)$ e verão $(0,40)$. (Tabela 1$)$

Foram encontrados 157 táxons de diatomáceas (Apêndice), distribuídos em 66 gêneros. Ocorreram espécies de água doce (26\%), salobra (50\%) e marinha (14\%). A maioria dos táxons (75\%) pertence à classe Bacilllariophyceae, enquanto $17 \%$ são da classe Coscinodiscophyceae e $8 \%$ da classe Fragillariophyceae. Nitzschia foi o gênero com maior número de táxons (22), sete dos quais foram abundantes: $N$. filiformis var. conferta, $N$. filiformis var. filiformis, N. frustulum, N. palea, N. spiculoides, $N$. subacicularis e $N$. subchoaerens var. scotica.

A maior riqueza ocorreu no verão (99 espécies) e no outono (90). Já na primavera, ocorreram 46 espécies e no inverno somente 29 . Vários táxons ocorreram em somente um período do ano: três espécies exclusivamente na primavera, quatro no inverno, 55 no verão e 39 no outono. Durante o período de estudo, 19 espécies ocorreram em todas as amostras, foram elas: Amphora charrua, Aulacoseira granulata, Bacillaria paxillifera, Catenula adhaerens, Cocconeis placentula, Gomphonema parvulum, H. tumida, Melosira varians, Navicula germanii, Navicula sp. 1, Nitzschia brevissima, N. filiformis, N. frustulum, Plagiogramma tenuissimum, Planothidium delicatulum, $P$. frequentissimum, Pseudostaurosira brevistriata, Pseudotaurosiropsis geocollegarum e Tabularia tabulata.

A seguir, são apresentadas 23 novas ocorrências de diatomáceas para o estado do Rio Grande do Sul (Figura 2):

\section{Amphora charrua (Figura 2H).}

Dimensões: ca. $18 \mu \mathrm{m}$ compr. e $4 \mu \mathrm{m}$ larg. Presente em todas as estações do ano. Habita sistemas aquáticos de água doce com moderado conteúdo eletrolítico no Uruguai. Pode ter sido encontrada em outras áreas da América do Sul, tendo sido confundida com A. montana Krasske, com a qual se assemelha na forma das valvas e frústulas. Distingue-se dela, no entanto, por apresentar valvas mais amplas no centro e ápices mais obtusos, porém menos flexionados. Amphora montana é cosmopolita e vive em hábitats subaéreos, enquanto $A$. charrua habita sistemas aquáticos dulcícolas com conteúdo eletrolítico moderadamente alto, e não em condições subaéreas (Metzeltin et al. 2005)

\section{Cocconeis peltoides (Figura $2 \mathrm{G}$ ).}

Dimensões: $10-12,6 \mu \mathrm{m}$ compr., ca. 7,3 $\mu \mathrm{m}$ larg. e 15-17 estrias em $10 \mu \mathrm{m}$. Apresenta distribuição cosmopolita oceânica, do Ártico aos trópicos, sendo comum no Mar Báltico (Witkowski et al. 2000). Assemelha-se a Cocconeis fluminensis var. subimpleta Peragallo \& Peragallo e C. pelta A.Schmidt. Entretanto, em $C$. peltoides, as estrias alcançam o esteno, enquanto em $C$. pelta não, e $C$. fluminensis var. subimpleta possui menor densidade de estrias (11-13 em $10 \mu \mathrm{m})$ (Sar et al. 2003).

Tabela 1. Variáveis físicas e químicas do Arroio Pseudônimo, Pelotas, Rio Grande do Sul, Brasil, entre maio de 2011 e janeiro de 2012. Temp.- temperatura da água; Cond.- condutividade elétrica; Prof.- profundidade; Transp.- transparência da água; PT- fósforo total; NT- nitrogênio total

\begin{tabular}{|c|c|c|c|c|c|c|c|c|}
\hline Período/variaveis & Temp. $\left({ }^{\circ} \mathrm{C}\right)$ & $\begin{array}{c}\text { Cond. } \\
\left.(\mathrm{mS} \mathrm{cm})^{-1}\right)\end{array}$ & pH & $\begin{array}{l}\text { Prof. } \\
\text { (m) }\end{array}$ & $\begin{array}{l}\text { Transp. } \\
\text { (Secchi) }\end{array}$ & $\begin{array}{r}\text { Vazão } \\
\left(\mathrm{m}^{3} \mathrm{~s}^{-1}\right)\end{array}$ & $\begin{array}{c}\text { PT } \\
\left(\mathrm{mg} \mathrm{L}^{-1}\right)\end{array}$ & $\begin{array}{c}\mathrm{NT} \\
\left(\mathrm{mg} \mathrm{L}^{-1}\right)\end{array}$ \\
\hline Outono (Maio 2011) & $18^{0}$ & 3.80 & 7.08 & 0.76 & Total & - & 0.09 & 0.29 \\
\hline Inverno (Agosto 2011) & $10^{0}$ & 0.65 & 8.65 & 0.80 & $0.20 \mathrm{~m}$ & 42.12 & 0.03 & 0.44 \\
\hline Primavera (Dezembro 2011) & $26^{0}$ & 3.43 & 7.82 & 0.35 & $0.23 \mathrm{~m}$ & 12.02 & 0.11 & 0.49 \\
\hline Verão (Janeiro 2012) & $24^{0}$ & 15.83 & 8.89 & 0.35 & Total & 9.4 & 0.04 & 0.40 \\
\hline
\end{tabular}


Entomoneis punctulata (Figura 2V).

Dimensões: ca. 36,6 $\mu \mathrm{m}$ compr. e $12 \mu \mathrm{m}$ larg. Observada somente no verão. É uma espécie marinha e salobra, com distribuição no Ártico e no Mar Báltico. Apresenta a frústula constricta no centro em vista conectival e é levemente silificada (Witkowski et al. 2000). Difere de outras espécies do gênero, como $E$. ornata e E. alata (Ehrenberg) Ehrenberg, pela frústula com estrias inconspícuas em microscopia óptica.

\section{Fallacia florinae (Figura 2J).}

Dimensões: ca. 9,2 $\mu \mathrm{m}$ compr., 4,6 $\mu \mathrm{m}$ larg., 35 estrias em $10 \mu \mathrm{m}$. Apresenta distribuição cosmopolita, em ambientes litorâneos marinhos e salobros (Witkowski et al. 2000).

\section{Karayevia oblongella (Figura $2 \mathrm{~F}$ ).}

Dimensões: 7,3-12,6 $\mu \mathrm{m}$ compr., 4,0-6,6 $\mu \mathrm{m}$ larg. e 13-16 estrias em $10 \mu \mathrm{m}$. Apresenta distribuição cosmopolita, ocorrendo na flora de água doce da Europa (Krammer \& Lange-Bertalot 1991b) e Brasil (Tremarin et al. 2009), onde foi citada como Achnanthes oblongella Østrup. Assemelha-se a Achnanthes lutheri Hustedt, diferindo por apresentar estrias mais afastadas da margem.

\section{Luticola simplex (Figura 2I).}

Dimensões: ca. $10 \mu \mathrm{m}$ compr., 5,3 $\mu \mathrm{m}$ larg., 25 estrias em $10 \mu \mathrm{m}$. Descrita para o Uruguai, no estuário do Rio da Prata (Metzeltin et al. 2005), assemelha-se a L. mutica (Kützing) D.G.Mann, diferindo pelas valvas rômbico-elípticas (vs. elípticas), com ápices obtusos, arredondados (vs. mais amplamente obtusos) e terminações da rafe flexionadas em direção oposta ao estigma, levemente dobradas em forma de gancho (Metzeltin et al. 2005).

\section{Mastogloia lanceolata (Figura 2M).}

Dimensões: ca. $50 \mu \mathrm{m}$ compr., 14,6 $\mu \mathrm{m}$ larg. e 19 estrias em $10 \mu \mathrm{m}$. Apresenta distribuição cosmoplita, comum em águas salobras e costas marinhas; na Europa, ocorre no Mediterrâneo e no mar Báltico (Witkowski et al. 2000). Assemelha-se a M. pumila (Cleve \& Möller) Cleve por apresentar estrias unisseriadas e rafe reta, diferindo pela ausência de esternos laterais.

\section{Navicula germainii (Figura 2L).}

Dimensões: ca. 26,6 $\mu \mathrm{m}$ compr., $6 \mu \mathrm{m}$ larg. e 16 estrias em $10 \mu \mathrm{m}$. Presente em todas as estações do ano. Foi encontrada em amostras do epilíton no Rio Sendai (Mar do Japão), ambiente sob influência marinha (Hirota \& Ohtsuka 2009). Registrada para o Uruguai (Metzeltin et al. 2005). Assemelha-se a $N$. rostellata, diferindo pelas valvas lanceoladas, ligeiramente mais estreitas no centro (vs. mais lineares) e pelas aréolas menos visíveis (Potapova 2011).
Navicula limata (Figura 2K).

Dimensões: ca. 13,3 $\mu \mathrm{m}$ compr., $6 \mu \mathrm{m}$ larg. e 30 estrias em $10 \mu \mathrm{m}$. Foi descrita para a costa de Camarões (África) e observada também em amostras marinhas do Caribe (Witkowski et al. 2000). Assemelha-se a $N$. limatoides Hustedt, diferindo por apresentar eixo apical menor e possuir maior número de estrias em $10 \mu \mathrm{m}$ (Foged 1984).

\section{Nitzschia fonticola var. pelagica (Figura 2Q).}

Dimensões: $26-28,6 \mu \mathrm{m}$ compr., 3,6-4 $\mu \mathrm{m}$ larg. e 12-14 fíbulas em $10 \mu \mathrm{m}$. Foi encontrada na Bolívia, em amostras do epilíton (Morales et al. 2007). Assemelha-se a $N$. pseudofonticola Hustedt, diferindo por apresentar estrias conspícuas em microscopia óptica e mais fíbulas em $10 \mu \mathrm{m}$.

\section{Nitzschia pararostrata (Figura 2R)}

Dimensões: ca. 14,5 $\mu \mathrm{m}$ compr., 8,6 $\mu \mathrm{m}$ larg. e 14 fíbulas e estrias transapicais pontuadas em $10 \mu \mathrm{m}$. Registrada somente na localidade-tipo (costa da Islândia), Países Baixos e planícies marinhas do Mar do Norte (Witkowski et al. 2000). Assemelha-se a Tryblionella compressa (Bailey) Poulin, porém é menor.

\section{Nitzschia spiculoides (Figura 2P).}

Dimensões: ca. 63,3 $\mu \mathrm{m}$ compr., 3,3 $\mu \mathrm{m}$ larg. e 11 fíbulas em $10 \mu \mathrm{m}$. Encontrada na África do Sul, em um rio de fluxo de água muito rápido, com $\mathrm{pH}$ 9,4 (Archibald 1966), e em amostras bênticas de marismas de Quivira (E.U.A.) (Harris \& Eberle 2001). Neste trabalho, foi abundante apenas no verão, estação com maior $\mathrm{pH}$, porém menor fluxo de água, oposto ao encontrado na África do Sul. Esta abundância maior no verão pode estar relacionada à maior condutividade elétrica. Assemelha-se a N. sigma por possuir a forma sigmoide, mas difere pelas fíbulas com maior espaçamento na região central e ausência de fíbulas alongadas.

\section{Opephora guenter-grassi (Figura 2E).}

Dimensões: ca. $6 \mu \mathrm{m}$ compr., $2,3 \mu \mathrm{m}$ larg. e 12 estrias em $10 \mu \mathrm{m}$. Foi uma das espécies mais abundantes nos sedimentos do litoral e sublitoral do Golfo de Gdansk (Witkowski 1994). Assemelha-se a O. mutabilis, porém é menor, possui esterno mais amplo, maior densidade de estrias e ausência de uma barra de espinhos marginal longitudinal.

\section{Petroneis marina (Figura 2U).}

Dimensões: $46 \mu \mathrm{m}$ compr., 20,6 $\mu \mathrm{m}$ larg. e 12 estrias em $10 \mu \mathrm{m}$. Espécie marinha e salobra que ocorre em áreas costeiras da Europa, incluindo o Mar Báltico (Witkowski et al. 2000). Assemelha-se a $P$. granulata (Bailey) D.G.Mann, diferindo por apresentar menor espaçamento das aréolas na região mediana da valva (Hendey 1964). 
Pinnularia meridiana (Figura 2O).

Dimensões: ca. $63 \mu \mathrm{m}$ compr., 10,6 $\mu \mathrm{m}$ larg. e 10 estrias em $10 \mu \mathrm{m}$. Assemelha-se a $P$. neomajor Krammer, diferindo por ser menor, com rafe filiforme (vs. complexa), esterno da rafe lanceolado (vs. linear) e área central mais ampla.

Plagiotropis lepidoptera var. proboscidea (Figura 2N). Dimensões: ca. $100 \mu \mathrm{m}$ compr., 16,6 $\mu \mathrm{m}$ larg. e 19 estrias em $10 \mu \mathrm{m}$. Apresenta distribuição cosmopolita. Foi encontrada no Uruguai, em um pequeno rio a montante da Laguna Rocha (Metzeltin et al. 2005). Assemelha-se a $P$. seriata (Cleve) Kuntze, diferindo pelas valvas elíptico-lanceoladas, extremidades apiculadas e aréolas inconspícuas.

\section{Pleurosigma salinarum (Figura 2X).}

Dimensões: 81,33 $\mu \mathrm{m}$ compr. e 9,3 $\mu \mathrm{m}$ larg. Encontrada em Cuba (Foged 1984) e no México (Fuerte et al. 2010), é uma espécie bêntica e cosmopolita que habita preferencialmente ambientes de água doce a moderadamente salobros (Fuerte et al. 2010). Assemelha-se a $P$. decorum W.Smith, mas é menor.

\section{Pseudopodosira echinus (Figura 2A).}

Dimensão: ca. 10,6 $\mu \mathrm{m}$ diâm. Abundante no verão. Descrita para o Uruguai (Metzeltin et al. 2005), assemelha-se à espécie-tipo do gênero, $P$. pileiformis A.P.Jousé, pela presença de espinhos na face valvar, diferindo pela ausência de ornamentação no centro da valva.

\section{Pseudostaurosira neoelliptica (Figura 2D).}

Dimensões: ca. 8,0 $\mu \mathrm{m}$ compr., 3,3 $\mu \mathrm{m}$ larg. e 14 estrias em $10 \mu \mathrm{m}$. Descrita para o Golfo de Gdansk como Fragilaria neoelliptica (Witkowski 1994), foi encontrada na Flórida (Morales 2002), tendo sido abundante no rio Caloosahatchee, ambiente eutrófico, com pH 7,5 e condutividade elétrica de $458 \mu \mathrm{S} \mathrm{cm}^{-1}$. É semelhante a Fragilaria sapotensis Witkowski \& Lange-Bertalot, diferindo pelas valvas menores e amplamente lanceoladas a elípticas (vs. amplamente lanceoladas), esterno amplamente lanceolado (vs. linear ou estreitamente lanceolado) e por apresentar menor densidade de estrias (Morales 2002).

\section{Pseudostaurosiropsis geocollegarum (Figura 2B).}

Dimensões: ca. 7,3 $\mu \mathrm{m}$ compr., 1,6 $\mu \mathrm{m}$ larg. e 20 estrias em $10 \mu \mathrm{m}$. A maior frequência desta espécie foi observada no período com maiores valores de condutividade elétrica $\left(15,83 \mathrm{mS} \mathrm{cm}^{-1}\right)$ e $\mathrm{pH}(8,89)$, o que concorda com a ecologia descrita por Morales (2002), que mencionou a espécie ocorrendo em águas com alta condutividade elétrica (458-1120 $\mu \mathrm{S} \mathrm{cm}^{-1}$ ), alcalinas $(\mathrm{pH} 7,1-8,3)$ e eutróficas. É típica de ambiente lagunar (Witkowski et al. 2000), tendo sido encontrada no sedimento do Golfo de Gdansk (Witkowski 1994) e no sul da Flórida (Morales 2002).
Assemelha-se a $P$. connecticutensis Morales, que ocorre com maior freqüência em águas mais alcalinas, com alta condutividade e condições eutróficas.

\section{Staurosira longirostris (Figura 2C).}

Dimensões: ca. 19,3 $\mu \mathrm{m}$ compr., 6,6 $\mu \mathrm{m}$ larg. e 19 estrias em $10 \mu \mathrm{m}$. Ocorre no Uruguai, na Lagoa Mirim e no Rio da Prata (Metzeltin et al. 2005). Assemelha-se a Staurosira stevensonii Manoylov, Morales \& Stoermer, diferindo pelo esterno central mais amplo (Manoylov et al. 2003).

\section{Surirella litoralis (Figura 2T).}

Dimensões: 14-21,3 $\mu \mathrm{m}$ compr., 8-10,6 $\mu \mathrm{m}$ larg. e 8 alas em $10 \mu \mathrm{m}$. Diatomácea marinha bentônica litorânea com distribuição conhecida para a Carolina do Norte (E.U.A.) (Hustedt 1955) e Golfo do México (Krayesky 2009). Difere de S. ovalis Brébisson e espécies similares por possuir sulcos mais amplos na ondulação da parede da célula, na qual a zona marginal não forma costelas, como em $S$. ovalis e outras espécies, e a projeção alar é mais distinta (Hustedt 1955).

Tryblionella limicola (Figura 2S).

Dimensões: ca. 21,3 $\mu \mathrm{m}$ compr., 8,6 $\mu \mathrm{m}$ larg. e 15 fíbulas em $10 \mu \mathrm{m}$. Encontrada no Rio da Prata e na Lagoa Mirim, Uruguai (Metzeltin et al. 2005). Assemelha-se a $T$. levidensis e $T$. debilis Arnott ex O’Meara, diferindo delas pelas estrias arredondadas visíveis ao miscroscópico óptico.

\section{DISCUSSÃO}

Acrostichum danaeifolium foi registrada para áreas de mangue (Coll et al. 2001; Mehltreter \& PalaciosRios 2003; Sharpe 2010) e sua pesença no Arroio Pseudônimo pode ser explicada pelas caracteríticas deste ambiente, como variação de salinidade, presença de margem sujeita às condições de alagamento e dessecação e sedimento mais fino, com maior acúmulo de material orgânico em decomposição do que outras áreas na Lagoa Pequena, como a Feitoria. Os maiores valores de riqueza de diatomáceas em $A$. danaeifolium ocorreram no verão e no outono, períodos em que a transparência atingiu toda a coluna d'água e a condutividade elétrica foi maior (Figura 3). No verão, a maior condutividade elétrica pode ter influenciado a ocorrência de maior número de espécies marinhas (Figura 4). No inverno, a menor riqueza parece ter sido influenciada por fatores como temperatura mais baixa, maior vazão e menor condutividade elétrica. O fluxo de água pode influenciar a riqueza, visto que o menor valor de riqueza ocorreu no período de maior vazão (inverno) e o maior valor de riqueza ocorreu no período de menor vazão (verão). Por outro lado, não foi possível observar uma relação direta entre a quantidade de nutrientes (fósforo e nitrogênio) e as 

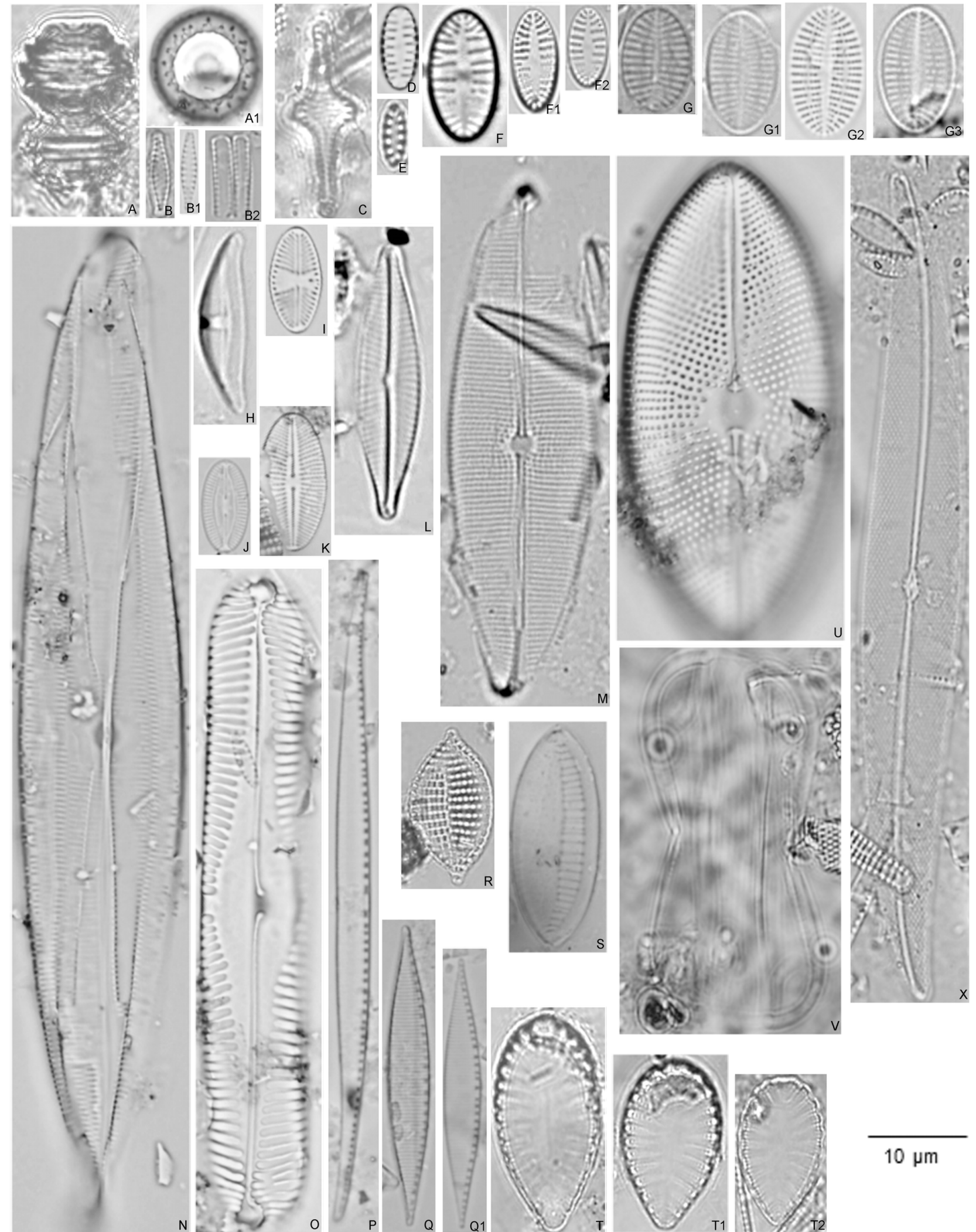

M
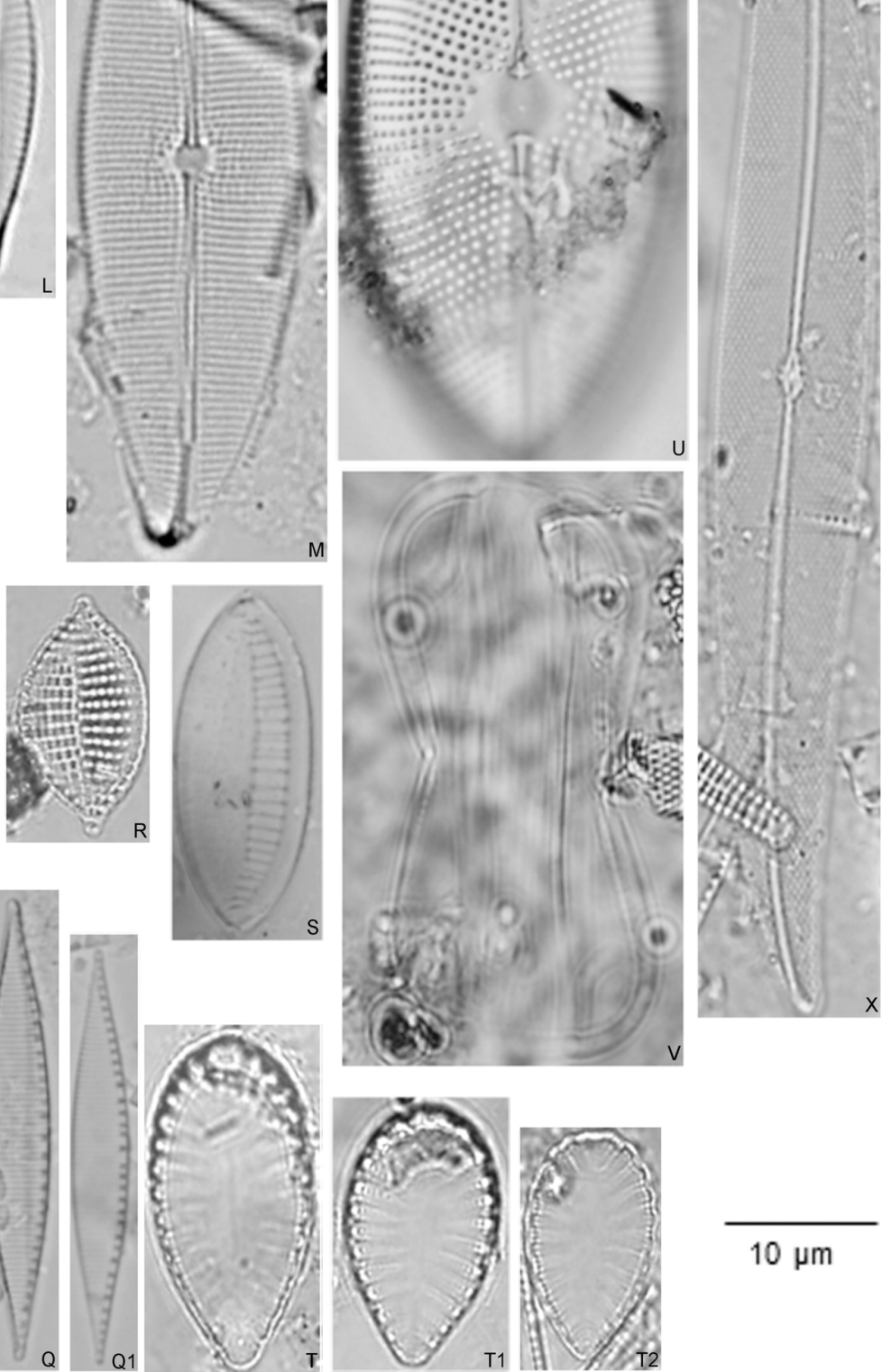

$10 \mu \mathrm{m}$

Figura 2. Espécies do Arroio Pseudônimo, Pelotas, Rio Grande do Sul, Brasil, registradas pela primeira vez no Estado: A- Pseudopodosira echinus; B- Pseudostaurosiropsis geocollegarum; C- Staurosira longirostris; D- Pseudostaurosira neoelliptica; E- Opephora guentergrassi; F- Karayevia oblongella; G- Cocconeis peltoides; H- Amphora charrua; I- Luticola simplex; J- Fallacia florinae; K- Navicula limata; L- Navicula germainii; M- Mastogloia lanceolata; N- Plagiotropis lepidoptera var. proboscidea; O- Pinnularia meridiana; P- Nitzschia spiculoides; Q- Nitzschia fonticola var. pelagica; R- Nitzschia pararostrata; S- Tryblionella limicola; T- Surirella litoralis; U- Petroneis marina; V- Entomoneis punctulata; X- Pleurosigma salinarum. 


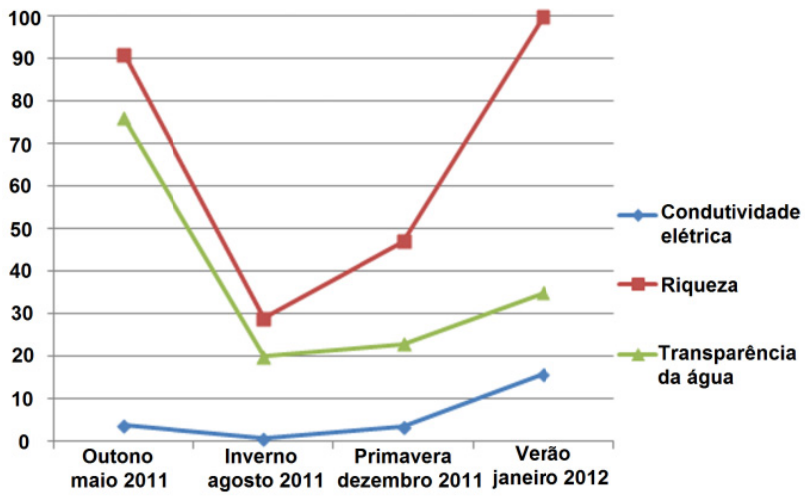

Figura 3. Relação entre riqueza de espécies, condutividade elétrica $\left(\mathrm{mS} \mathrm{cm}^{-1}\right)$ e transparência da água (Secchi em $\mathrm{cm}$ ), entre maio de 2011 e janeiro de 2012, no Arroio Pseudônimo, Pelotas, Rio Grande do Sul, Brasil.

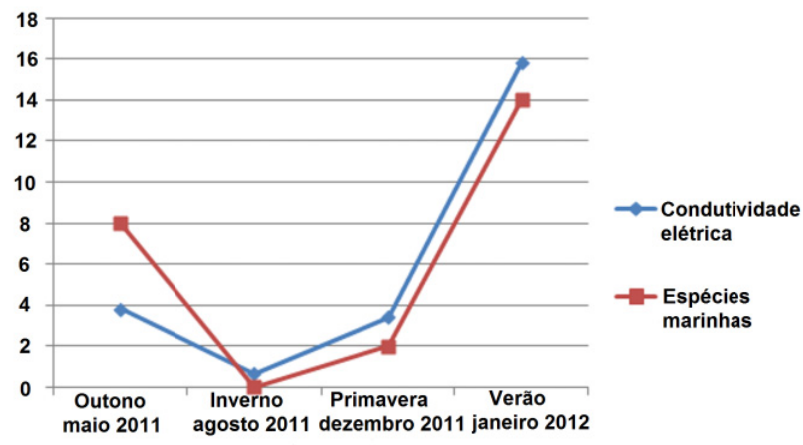

Figura 4. Relação entre a condutividade elétrica $\left(\mathrm{mS} \mathrm{cm} \mathrm{cm}^{-1}\right)$ e número total de espécies marinhas, entre maio de 2011 e janeiro de 2012, no Arroio Pseudônimo, Pelotas, Rio Grande do Sul, Brasil.

diatomáceas, pois no Arroio Pseudônimo, o fósforo esteve dentro dos limites para águas salobras da classe 1 e o nitrogênio foi semelhante a locais não impactados da Lagoa dos Patos (CONAMA 2005; Salomoni \& Torgan 2008).

Gaiser et al. (2010) amostraram várias espécies de plantas em parcelas de $1 \mathrm{~m}^{2}$ distribuídas em 484 locais de áreas úmidas costeiras subtropicais, nos Everglades (Flórida, E.U.A.), Black River (Jamaica), New River e Reserva da Biosfera Sian Ka'na (México), identificando 124, 72, 98 e 68 táxons, respectivamente. Já na Baía da Flórida, foram registados 592 táxons. Este valor de riqueza, no entanto, deve estar relacionada ao maior número de locais amostrados naquela região. No Arroio Pseudônimo, $A$. danaeifolium foi amostrada em uma área menor, porém a riqueza encontrada foi maior do que na maioria das áreas úmidas da Flórida, mostrando a importância desta samambaia para a biodiversidade da Lagoa Pequena.

A riqueza de diatomáceas registrada para o Arroio Pseudônimo neste estudo também foi maior do que em áreas úmidas estuarinas da Argentina, onde Gómez et al. (2003) encontraram 57 espécies no estúario do Rio da Prata, sobre Scirpus californicus (Mey) Steud, que foi a planta dominante neste ambiente, em locais de coleta mais expostos às variações ambientais do Oceâno Atlântico. A maior riqueza no Arroio Pseudônimo pode estar associada à sua inserção no sistema estuarino. Além disso, trata-se de um ambiente protegido por banhados e constituído por diversas espécies de plantas, o que proporciona uma maior riqueza de micro-hábitats, favorecendo a presença e a permanência de mais espécies de diatomáceas.

Alves et al. (2009) afirmaram que as variações ambientais sazonais na Lagoa Pequena propiciam condições para a presença de espécies de peixes estuarinos e não limitam a presença das espécies de água doce. As conexões com a Lagoa dos Patos atavés dos arroios Pseudônimo, Tapado, Canaleta da Feitoria e sangradouro mostra que a Lagoa Pequena é um sistema complexo integrante do sistema estuarino, como foi mostrado pela ocorrência de espécies de diatomáceas salobras, marinhas e de água doce em todas as estações do ano.

Segundo Ferreira \& Seeliger (1985), Cocconeis placentula representou um estágio pioneiro de colonização em folhas de Ruppia maritma L. no estuário da Lagoa dos Patos, e a dominância de Tabularia fasciculata favoreceu a fixação de espécies de Amphora Ehrenberg e Nitzschia, além de algumas espécies naviculoides. Em A. danaeifolium, C. placentula, foi encontrada em todas as estações do ano, e abundante na primavera e no verão. A riqueza nestas estações do ano e a ocorrência de várias espécies abundantes durante todo o período de estudo parece indicar que a comunidade de diatomáceas associadas a A. danaeifolium não se encontrava em estágios iniciais de colonização. Tabularia fasciculata foi abundante somente no outono, mas Nitzschia subchoaerens var. scotica foi a espécie mais abundante (Apêndice 1). Juntos estes dois táxons parecem ter contribuído para a fixação de outras 39 espécies que só ocorreram nesta estação.

Acrostichum danaeifolium representa um importante microhábitat para o crescimento de diatomáceas epífitas na Lagoa Pequena, oferecendo substrato para espécies de água doce, salobras e marinhas. A alta riqueza de espécies de diatomáceas epífitas encontrada no Arroio Pseudônimo aponta para a necessidade de preservação da Lagoa Pequena, como enfatizado pela Base de Dados Tropicais (2003).

\section{AgRAdeCIMENTOS}

À Coordenação de Aperfeiçoamento de Pessoal de Nível Superior (CAPES), pela bolsa de mestrado à primeira autora; ao laboratório de histologia da Universidade Federal de Rio Grande (FURG), por disponibilizar o microscópio para captura de imagem digital. 


\section{REFERÊNCIAS}

Alves, C.; Corrêa, F. \& Bager, A. 2009. Ictiofauna capturada por pescadores artesanais na Lagoa Pequena - Região estuarina da Lagoa dos Patos - RS. Biotemas 22: 229-234.

Archibald, R.E.M. 1966. Some new and rare Nitzschiae (Diatomaceae) from the Vaal Dam Catchment area (South Africa). Portugaliae Acta Biologica séries B 8: 227-238.

Base de Dados Tropicais 2003. Avaliação da Situação e Ações Prioritárias para a Conservação da Zona Costeira da Região Sul - Rio Grande do Sul e Santa Catarina. Disponível em $<$ http://www.bdt.fat.org.br/workshop/costa/sul parte3>; acesso em 27 mar. 2003.

Baumgarten, M.G.Z.; Rocha, J.M.B. \& Niencheski, L.F.H. 1996. Manual de Análises em Oceanografia Química. Editora da FURG, Rio Grande.

Bertolli, L.M.; Tremarin, P.I. \& Ludwig, T.A.V. 2010. Diatomáceas perifíticas em Polygonum hydropiperoides Michaux, reservatório do Passaúna, Região Metropolitana de Curitiba, Paraná, Brasil. Acta Botanica Brasilica 24: 10651081.

Carvalho, T.M. 2008. Técnicas de medição de vazão por meios convencionais e não convencionais. Revista Brasileira de Geografia Física 1: 73-85.

Chen, C.P.; Gao, Y.H. \& Lin, P. 2010. Geographical and seasonal patterns of epiphytic diatoms on a subtropical mangrove (Kandelia candel) in southern China. Ecological Indicators 10 143-147.

Coll, M.; Fonseca, A.C. \& Cortés, J. 2001. El manglar y otras asociaciones vegetales de la laguna de Gandoca, Limón, Costa Rica. Revista de Biologia Tropical 49: 321-329.

CONAMA (Conselho Nacional do Meio Ambiente) 2005. Resolução CONAMA $\mathrm{n}^{0} 357$ de 2005. Disponível em $<$ http://www.mma.gov.br/port/conama/res/res05/res35705.pdf>; acesso em 17 set. 2012

Farias, R.P. \& Xavier, S.R. 2011. Fenologia e sobrevivência de três populações de samambaias em remanescente de Floresta Atlântica Nordestina, Paraíba, Brasil. Biotemas 24: 13-20.

Ferreira, S. \& Seeliger, U. 1985. The colonization process of algal epiphytes on Ruppia maritma L. Botanica Marina 28: 245-249.

Flôres, L.T.; Moreira-Filho, H. \& Ludwig, T.A.V. 1999. Contribuição ao inventário florístico das diatomáceas (Bacillariophyta) do Banhado do Taim, Rio Grande do Sul, Brasil: Epithemia Brébisson ex Kützing, Rhopalodia O. Müller e Surirella Turpin. Insula 28: 149-166.

Foged, N. 1984. Freshwater and Littoral Diatoms from Cuba Bibliotheca Diatomologica. Vol. 5. J. Cramer, Vaduz.

Fuerte, F.O.L.; Siqueiros-Beltrones, D.A. \& Navarro, R.N. 2010. Benthic Diatoms Associated with Mangrove Environments in the Northwest Region of México. CICIMAR-Oceánides, La Paz, México.

Gaiser, E.; Hée, J.M.; Tobias, F.A.C. \& Wachnicka, A.H. 2010 Mastogloia smitii var. lacustris Grun.: engineer of calcareous mats in karstic subtropical wetlands. Proceedings of the Academy of Natural Sciences of Philadelphia 160: 99-112.

Gómez, N.; Licursi, M. \& Hualde, R.R. 2003. Epiphytic algae on the bulrush (Scirpus californicus (Mey) Steud) in the Río de la Plata (Argentina): structure and architeture. Archiv für Hydrobiologie, Supplementband 147(3-4): 231-247.
Harris, M.R. \& M.E. Eberle. 2001. Diatoms (Bacillariophyta) from saline waters within Quivira National Wildlife Refuge, Stafford County, Kansas. Southwestern Naturalist 46: 200-207.

Hendey, N.I. 1964. An introductory account of the smaller algae of British coastal waters. Part V. Bacillariophyceae (Diatoms). In: Fishery Investigations Series. Vol. 4. Koeltz ScientificBooks Koenigstein, London.

Hirota, M \& Ohtsuka, T. 2009. Epilithic diatoms of Sendai River, Tottori Prefecture, Japan. Diatom 25: 52-72.

Hustedt, F.V. 1930. Kryptogamen-Flora von Deutschland, Österreich und der Schweiz. Band VII. Die Kieselalgen. Teil 1. Koeltz Scientific Books, Königstein.

Hustedt, F.V. 1955. Marine Littoral Diatoms of Beaufort, North Carolina. Duke University Press, Durham.

Jensen, N.C. 1985. Hustedt's "Die Kieselalgen, 2. Teil": The Pennate Diatoms. Koeltz Scientific Books, Koenigstein.

Krammer, K. \& Lange-Bertalot, H. 1991a. Bacillariophyceae: Centrales, Fragilariaceae, Eunotiaceae. In: H. Ettl, G. Gärtner, J. Gerloff, H. Heynig \& D. Mollenhauer (eds), Süsswasserflora von Mitteleuropa. Vol. 3, parte 3. G. Fischer, Stuttgart \& Jena.

Krammer, K. \& Lange-Bertalot, H. 1991b. Bacillariophyceae: Achnanthaceae. Kritische Ergänzungen zu Navicula (Lineolatae) und Gomphonema. In: H. Ettl, G Gärtner, J. Gerloff, H. Heynig \& D. Mollenhauer (eds), D. Süsswasserflora von Mitteleuropa. Vol. 2, parte 4. G. Fischer, Sttugart \& Jena.

Krayesky, D.M.; Castillo, E.M.; Zamudio, E.; Norris, J.N. \& Frederiq, S. 2009. Diatoms (Bacillariophyta) of the Gulf of Mexico. In: D.L. Felder \& D.K. Camp (eds), Gulf of Mexico Origin, Waters, and Biota. Vol. 1. Biodiversity. Texas A\&M University Press, College Station, p. 155-186.

Ludwig, T.A.V.; Flores, T.L.; Moreira-Filho, H. \& Veiga, L.A.S. 2004. Inventário florístico das diatomáceas (Ochrophyta) de lagoas do Sistema Hidrológico do Taim, Rio Grande do Sul, Brasil: Coscinodiscophyceae. Iheringia série Botânica 59: 97106.

Mackereth, J.F.H.; Heron, J. \& Talling, J.F. 1978. Water analysis: some revised methods for limnologists. Freshwater Biological Association, Scientific Publication 36. Titus Wilson \& Sons Ltda, Kendal.

Maltichik, L.; Stenert, C.; Kotzian, CB. \& Pereira, D. 2010. Responses of freshwater molluscs to environmental factors in Southern Brazil wetlands. Brazilian Jounal of Biology 70: 473482.

Manoylov, K.M.; Morales, E.A. \& Stoermer, E.F. 2003 Staurosira stevensonii sp. nov. (Bacillariophyta), a new taxon from Florida, USA. European Journal of Phycology 38: 65-71.

Marcon, A.B. 2000. Citotaxonomia das Espécies de Acrostichum L. (Pteridaceae) ocorrentes no Nordeste Brasileiro. Dissertação de mestrado. Universidade Federal de Pernambuco.

Mehltreter, K. \& Palacios-Rios, M. 2003. Phenological studies of Acrostichum danaeifolium (Pteridaceae, Pteridophyta) at a mangrove site on the Gulf of Mexico. Journal of Tropical Ecology 19: 155-162.

Metzeltin, D.; Lange-Bertalot, H. \& García-Rodríguez, F. 2005. Diatoms of Uruguay. In: H. Lange-Bertalot (ed.), Iconographia Diatomologica. Vol. 15. Koeltz Scientific Books, Königstein.

Morales, E.A. 2002. Studies in selected fragilarioid diatoms of potential indicator value from Florida (USA) with notes on the genus Opephora Petit (Bacillariophyceae). Limnologica 32: 102-113. 
Morales, E.A.; Vis, M.L.; Fernández, E. \& Kocioleck, P. 2007. Epilithic diatoms (Bacillariophyta) from cloud forest and alpine streams in Bolivia, South America II: a preliminary report on the diatoms from Sorata, Department of La Paz. Acta Nova 3: 680-696.

Moschini-Carlos, V. 1999. Importância, estrutura e dinâmica da comunidade perifítica nos ecossistemas aquáticos continentais. In: M.L.M. Pompêo (ed.), Perspectivas na Limnologia no Brasil. Gráfica e Editora União, São Luís, p. 1-11.

Potapova, M. 2011. Navicula germainii. In: Diatoms of the United States. Disponível em< http://westerndiatoms.colorado.edu/ taxa/species/navicula_germainii >; acesso em $12 \mathrm{dez} .2011$.

Salomoni, S.E. \& Torgan, L.C. 2008. Diatomáceas epilíticas indicadoras de graus de contaminação orgânica no Lago Guaíba do extremo sul do Brasil. Acta Limnologica Brasilica 20: 313 324.

Santos, E.M.; Tremarin, P.I. \& Ludwig, T.A.V. 2011. Diatomáceas perifíticas em Potamogeton polygonus Cham. \& Schltdl., citações pioneiras para o estado do Paraná. Biota Neotropica 11: 303-315.

Sar, E.A. 2003. Cocconeis Ehrenberg and Psammococconeis Garcia (Bacillariophyta) from the gulf of san Matías, Patagonia, Argentina. Diatom Research 18: 79-106.

Sehnem, A.S.J. 1972. Pteridáceas. In: P.R. Reitz (ed.), Flora Ilustrada Catarinense. Herbário Barbosa Rodrigues, Itajaí, p. 229-232.

Sharpe, J.M. 2010. Responses of the mangrove fern Acrostichum danaeifolium Langsd. \& Fisch. (Pteridaceae, Pteridophyta) to disturbances resulting from increased soil salinity and hurricane
Georges at the Jobos Bay National Estuarine Research reserve, Porto Rico. Wetlands Ecology and Management 18: 57-68.

Simonsen, R. 1974. The diatom plankton of the Indian Ocean Expedition of R/V Meteor" 1964-65. METEOR Forsch.Ergebnisse, Reihe D. 1974 19: 1-107.

Simonsen, R. 1987a. Atlas and Catalogue of the Diatom Types of Friedrich Hustedt. Vol. 2. J. Cramer, Stuttgart.

Simonsen, R. 1987b. Atlas and Catologue of the Diatom Types of Friedrich Hustedt. Vol. 3. J. Cramer, Stuttgart.

Torgan, L.C.; Becker, V. \& Prates, H.M. 1999. Checklist das diatomáceas (Bacillariophyceae) de ambientes de águas continentais e costeiros do Estado do Rio Grande do Sul. Iheringia série Botânica 52: 89-144.

Tremarin, P.I.; Freire, E.G.; Bertolli, L,M. \& Ludwig, T.A.V. 2009. Catálogo das diatomáceas (Ochrophyta-Diatomeae) continentais do estado do Paraná. Iheringia série Botânica 64: 79-107.

Tryon, R.M. \& Tryon, A.F. 1982. Ferns and Allied Plants with Special Reference to Tropical America. Springer-Verlag, New York.

Valderrama, J.C. 1981. The simultaneous analisys of total nitrogen and phosphorus in natural waters. Marine Chemistry 10: 109122.

Witkowski, A. 1994. Recent and fossil diatom flora of the Gulf of Gdansk, Southern Baltic Sea. Origin, composition and changes of diatom assemblages during the Holocene. Bibliotheca Diatomologica. Vol. 28, J. Cramer, Stuttgart.

Witkowski, A.; Lange-Bertalot, H. \& Metzeltin, D. 2000. Diatom flora of marine coasts I. Iconographia Diatomologica. Vol. 7. R.G. Gantner Verlag K.G., Ruggell. 
Apêndice. Lista dos táxons de diatomáceas em A. danaeifolium no Arroio Pseudônimo, Pelotas, Rio Grande do Sul, Brasil, mostrando a abundância (\%) e a ocorrência nas estações do ano (“+” presença, e "_" ausência). As espécies abundantes aparecem em negrito; * indica novo registro para o estado do Rio Grande do Sul.

\begin{tabular}{|c|c|c|c|c|}
\hline & Outono & Inverno & Primavera & Verão \\
\hline & Maio & Agosto & Dezembro & Janeiro \\
\hline & 2011 & 2011 & 2011 & 2012 \\
\hline Achnanthes brevipes Agardh & 0,4 & - & - & - \\
\hline Achnanthes curvirostrum Brun & - & - & - & + \\
\hline Achnanthes inflata (Kützing) Grunow & - & - & - & 0,4 \\
\hline Actinoptychus cf. concentricus A.W.F.Schmidt & - & - & - & + \\
\hline Actinoptychus aff. heliopelta Grunow & - & - & - & + \\
\hline Actinoptychus senarius (Ehrenberg) Ehrenberg & + & - & - & - \\
\hline Amphora charrua Metzeltin, Lange-Bertalot \& García- & $0,2-0,4$ & 0,4 & $0,4-1,3$ & $0,4-0,9$ \\
\hline \multicolumn{5}{|l|}{ Rodriguez* } \\
\hline Amphora copulata (Kützing) Schoeman \& Archibald & 0,4 & - & $0,9-2,7$ & $0,9-1,6$ \\
\hline Amphora profusa Giffen & 0,2 & - & - & - \\
\hline Amphora sabiniana Reimer & $0,6-3,5$ & - & $0,9-3,4$ & $0,8-1,9$ \\
\hline Amphora subholsatica Krammer & $0,4-0,6$ & - & - & - \\
\hline Amphora aff. gacialis W.Smith & + & - & - & - \\
\hline Anomoeoneis sphaerophora E.Pfitzer & - & - & - & + \\
\hline Aulacoseira italica (Ehrenberg) Simonsen & - & - & - & + \\
\hline Aulacoseira granulata (Ehrenberg) Simonsen & 0,4 & 0,4 & 0,4 & 2,3 \\
\hline Auliscus sculptus (W.Smith) Ralfs in Pritchard & - & - & - & + \\
\hline Bacillaria paxillifera (O.F.Müller) T.Marsson & $2,8-7,3$ & $0,4-3,6$ & $0,4-5,3$ & $0,4-3,6$ \\
\hline Biremis circumtexta (Meister ex Hustedt) H.Lange-Bertalot & 0,4 & - & 0,5 & $0,4-1,9$ \\
\hline \multicolumn{5}{|l|}{ \& A.Witkowski } \\
\hline Caloneis permagna (J.W.Bailey) Cleve & - & - & - & + \\
\hline Caloneis westii (Wm.Smith) Hendey & - & - & - & 0,4 \\
\hline Capartogramma crucicola (Grunow) Ross & 0,2 & - & 0,8 & - \\
\hline Catenula adhaerens (Mereschkowsky) Mereschkowsky & $0,6-1,2$ & $0,4-1,9$ & $0,4-2,9$ & $1,2-3,3$ \\
\hline Chamaepinnularia truncata (Dieter König) Witkowski & + & - & - & - \\
\hline Cocconeis fluviatilis Wallace & $\mathbf{2 , 1 - 5 , 7}$ & - & $0,4-2,5$ & - \\
\hline Cocconeis hauniensis A.Witkowski & $0,2-1,2$ & - & - & - \\
\hline Cocconeis peltoides Hustedt* & $0,2-0,4$ & - & - & - \\
\hline Cocconeis placentula Ehrenberg & $0,2-2,0$ & $0,4-1,8$ & $0,4-4,6$ & $0,8-4,7$ \\
\hline Cocconeis sp. & $0,7-1,3$ & - & - & $1,4-2,9$ \\
\hline Cosmioneis pusilla (W.Smith) D.G.Mann \& A.J.Stickle & + & - & - & - \\
\hline Ctenophora pulchella (Ralfs ex Kützing) Williams \& Round & - & $0,4-3,3$ & 1 & - \\
\hline Cyclotella atomus Hustedt & + & - & - & - \\
\hline Cyclotella meneghiniana Kützing & 0,4 & - & 0,5 & 0,4 \\
\hline Cyclotella striata (Kützing) Grunow & - & - & - & 0,4 \\
\hline Cyclotella stylorum Brightwell & - & - & - & + \\
\hline Denticula kuetzingii Grunow & $0,4-0,7$ & - & - & 0,4 \\
\hline Desikaneis gessneri (Hustedt) Prasad & 0,2 & - & - & 0,4 \\
\hline Diadesmis contenta (Grunow ex Van Heurck) D.G.Mann & $1,6-2,2$ & - & - & - \\
\hline Diploneis elliptica (Kütz.) Cleve & 0,2 & - & - & - \\
\hline Diploneis ovalis (Hilse) Cleve & 0,2 & - & 0,4 & $0,4-2,0$ \\
\hline Diploneis puella (Schumann) Cleve & 0,2 & - & - & $0,8-0,9$ \\
\hline Diploneis smithii (Brébisson) Cleve & - & - & - & 0,4 \\
\hline
\end{tabular}




\begin{tabular}{|c|c|c|c|c|}
\hline \multicolumn{5}{|l|}{ Apêndice (continuação) } \\
\hline & Outono & Inverno & Primavera & Verão \\
\hline & Maio & Agosto & Dezembro & Janeiro \\
\hline & 2011 & 2011 & 2011 & 2012 \\
\hline Encyonema silesiacum (Bleisch) D.G.Mann & - & $0,4-0,9$ & 0,4 & - \\
\hline Entomoneis ornata (Bailey) Reimer & - & - & - & $\mathbf{0 , 8 - 2 , 8}$ \\
\hline Entomoneis punctulata (Grunow) Osada \& Kobayasi* & - & - & - & 0,4 \\
\hline Epithemia sp. & - & - & - & + \\
\hline Eunotia bilunaris (Ehrenberg) Schaarschmidt & - & + & - & - \\
\hline Eunotia diodon Ehrenberg & + & - & - & - \\
\hline Eunotia major (W.Smith) Rabenhorst & - & - & - & + \\
\hline Eunotia sudetica O.Müller & - & - & + & - \\
\hline Eunotogramma $\mathrm{sp}$. & + & - & - & - \\
\hline Fallacia florinae (M. Møller) Witkowski* & + & - & - & - \\
\hline Fallacia pygmaea (Kützing) Strickle \& Mann & 0,2 & - & - & - \\
\hline Fallacia tenera (Hustedt) D.G.Mann & - & - & - & + \\
\hline Fallacia sp. & $0,2-0,6$ & - & $0,4-2,1$ & $0,8-3,2$ \\
\hline Fragilaria capucina Desmazières & - & - & - & + \\
\hline Gomphonema affine Kützing & 0,4 & $0,4-8,9$ & - & - \\
\hline Gomphonema gracile Ehrenberg & - & $0,4-0,8$ & - & - \\
\hline Gomphonema parvulum (Kützing) Kützing & $0,8-1,4$ & $7,1-10,5$ & $0,4-2,4$ & 0,4 \\
\hline Gyrosigma sp. & - & - & - & $0,8-0,9$ \\
\hline Halamphora tenerrima (Aleem \& Hustedt) Levkov & 0,2 & - & - & - \\
\hline Halamphora tumida (Hustedt) Levkov & 0,2 & 0,4 & $0,4-0,9$ & 0,4 \\
\hline \multicolumn{5}{|l|}{ \& Witkowski } \\
\hline Hyalodiscus scoticus (Kützing) Grunow & $0,2-0,4$ & - & - & 0,4 \\
\hline Karayevia oblongella (Østrup) M.Aboal* & 0,4 & - & - & - \\
\hline Lemnicola hungarica (Grunow) Round \& Basson & 0,2 & - & - & - \\
\hline Luticola goeppertiana (Bleisch) D.G.Mann & + & - & - & - \\
\hline $\begin{array}{l}\text { Luticola simplex Metzeltin Lange-Bertalot \& Garcia- } \\
\text { Rodrigues* }\end{array}$ & - & - & - & 0,4 \\
\hline Luticola sp. 1 & + & - & - & - \\
\hline Luticola sp. 2 & + & - & - & - \\
\hline Mastogloia elliptica (C.Agardh) Cleve & + & - & - & - \\
\hline Mastogloia lanceolata Thwaites in W.Smith* & + & - & - & - \\
\hline Mastogloia pumila (Cleve \& Möller) Cleve & - & - & - & + \\
\hline Mastogloia smithii var. lacustris Grunow & + & - & - & - \\
\hline Melosira moniliformis (Müller) Agardh & - & - & - & 2,8 \\
\hline Melosira varians Agardh & 0,2 & $0,4-3,8$ & 0,4 & $0,8-2,8$ \\
\hline Navicula germainii Wallace* & $0,4-0,8$ & $0,4-0,9$ & $0,4-1,9$ & $0,4-1,2$ \\
\hline Navicula gregaria Donkin & + & - & - & - \\
\hline Navicula limata Hustedt* & - & - & - & + \\
\hline $\begin{array}{l}\text { Navicula norae Metzeltin, Lange-Bertalot \& García- } \\
\text { Rodríguez }\end{array}$ & - & - & 0,4 & $0,4-1,2$ \\
\hline Navicula recens (Lange-Bertalot) Lange-Bertalot & 0,2 & - & - & - \\
\hline Navicula aff. rostellata Kützing & + & - & - & - \\
\hline Navicula schroeteri Meister & $0,8-1,7$ & - & - & - \\
\hline
\end{tabular}




\begin{tabular}{|c|c|c|c|c|}
\hline \multicolumn{5}{|l|}{ Apêndice (continuação) } \\
\hline & Outono & Inverno & Primavera & Verão \\
\hline & Maio & Agosto & Dezembro & Janeiro \\
\hline & 2011 & 2011 & 2011 & 2012 \\
\hline Navicula sp. 1 & $0,4-3,4$ & 33-39,5 & $3,8-12,5$ & $0,8-1,6$ \\
\hline Navicula sp. 2 & $1,4-2,1$ & - & $1,3-3,3$ & $1,4-1,9$ \\
\hline Nitzschia amphibia Grunow & + & - & - & - \\
\hline Nitzschia brevissima Grunow & 0,4 & 0,8 & 0,9 & 0,4 \\
\hline Nitzschia clausii Hantzsch & $0,4-3,0$ & 0,4 & - & - \\
\hline Nitzschia dissipata var. borneensis Hustedt & 0,4 & - & - & - \\
\hline Nitzschia filiformis var. conferta (Richter) Lange-Bertalot & $1,2-3,5$ & - & $2,9-4,2$ & 2,8 \\
\hline Nitzschia filiformis (W.Smith) Hustedt var. filiformis & $4,6-7,6$ & $0,8-2,8$ & $1,9-7,9$ & $0,4-0,9$ \\
\hline Nitzschia fonticola var. pelagica Hustedt* & 1,9 & 0,4 & - & - \\
\hline Nitzschia frustulum (Kützing) Grunow & $0,4-4,7$ & $0,4-49$ & $0,9-35$ & $0,8-4,2$ \\
\hline Nitzschia gracilis Hantzsch & - & - & - & $1,2-1,7$ \\
\hline Nitzschia intermedia Hantzsch ex Cleve \& Grunow & - & - & - & $1,6-2,9$ \\
\hline Nitzschia microcephala Grunow & 1 & - & - & - \\
\hline Nitzschia nana Grunow & - & + & - & - \\
\hline Nitzschia palea (Kützing) W.Smith & $6,5-8,8$ & - & - & $0,9-7,1$ \\
\hline Nitzschia pararostrata (Lange-Bertalot) Lange Bertalot* & - & - & - & + \\
\hline Nitzschia pumila Hustedt & 0,4 & - & - & - \\
\hline Nitzschia reversa W.Smith & 0,2 & - & 0,5 & 0,4 \\
\hline Nitzschia scalpeliformis Grunow & 0,4 & - & - & - \\
\hline Nitzschia sigma (Kützing) W.Smith & 0,2 & - & 1,7 & $0,4-1,2$ \\
\hline Nitzschia spiculoides Hustedt* & 0,2 & - & - & $9,8-15,3$ \\
\hline Nitzschia subacicularis Hustedt & - & - & - & $2,3-14,3$ \\
\hline Nitzschia subcohaerens var. scotica (Grunow) van Heurck & 19,0-20,7 & - & 2,4-14 & - \\
\hline Nitzschia sp. & $0,9-1,8$ & 1,8 & - & - \\
\hline Opephora guenter-grassi (Witkowski \& Lange Bertalot) & - & - & - & + \\
\hline \multicolumn{5}{|l|}{ Sabbe \& Vyverman* } \\
\hline Opephora mutabilis (Grunow) Sabbe \&Vyverman & - & - & - & + \\
\hline Paralia sulcata (Ehrenberg) Cleve & - & - & - & + \\
\hline \multicolumn{5}{|l|}{ Lange-Bertalot \& Metzeltin } \\
\hline Petroneis marina (Ralfs) D.G.Mann* & - & - & - & + \\
\hline Pinnularia acrosphaeria W.Smith & - & - & - & + \\
\hline Pinnularia meridiana Metzeltin \& Krammer* & - & - & - & + \\
\hline Pinnularia viridiformis Krammer & - & - & - & + \\
\hline Placoneis sovereignae (Hustedt) Torgan \& Donadel & - & - & - & 0,4 \\
\hline Plagiogramma tenuissimum Hustedt & $5,5-9,6$ & $0,8-5,1$ & $8,4-12,1$ & $9,5-13,7$ \\
\hline Plagiogramma tenuistriatum Cleve & - & - & - & + \\
\hline $\begin{array}{l}\text { Plagiotropis lepidoptera (Gregory) Reimer var. proboscidea } \\
\text { (Cleve) Reimer* }\end{array}$ & - & - & 0,5 & $0,4-0,9$ \\
\hline Planothidium delicatulum (Kütz.) Round \& Bukhtiyarova & $0,4-1,9$ & 0,4 & $0,4-2,3$ & $0,4-2,5$ \\
\hline $\begin{array}{l}\text { Planothidium frequentissimum (Lange-Bertalot) Round \& } \\
\text { L.Bukhtiyarova }\end{array}$ & $0,2-0,6$ & $1,3-5,1$ & $0,8-2,9$ & 0,4 \\
\hline Planothidium haukianum (Grunow) Round \& & $0,4-1,4$ & - & - & - \\
\hline L.Bukhtiyarova & & & & \\
\hline
\end{tabular}




\begin{tabular}{|c|c|c|c|c|}
\hline \multicolumn{5}{|l|}{ Apêndice (continuação) } \\
\hline & Outono & Inverno & Primavera & Verão \\
\hline & Maio & Agosto & Dezembro & Janeiro \\
\hline & 2011 & 2011 & 2011 & 2012 \\
\hline Planothidium lemmermannii (Hustedt) E.A.Morales & - & - & - & + \\
\hline Planothidium minutissimum (Krasske) Lange Bertalot & $0,2-, 4$ & - & $0,4-4,8$ & $1,9-5,4$ \\
\hline Pleurosigma salinarum (Grunow) Grunow* & 0,4 & - & $0,4-0,9$ & - \\
\hline Pleurosira laevis (Ehrenberg) Compère & - & - & 2,7 & - \\
\hline Psammodictyon sp. & $0,4-0,9$ & - & $0,4-3,2$ & $0,8-1,4$ \\
\hline Pseudopodosira echinus (Frenguelli) Metzeltin, Lange- & - & - & - & $1,9-2,3$ \\
\hline \multicolumn{5}{|l|}{ Bertalot \& García-Rodríguez* } \\
\hline Pseudostaurosira brevistriata (Grunow) Williams \& Round & $1,9-3,4$ & $1,9-10$ & $11,1-28,4$ & $18,5-31,1$ \\
\hline Pseudostaurosira neoelliptica (Witkowski) Morales* & - & - & - & + \\
\hline Pseudostaurosiropsis geocollegarum & 6,3 & 0,4 & $0,5-0,9$ & $0,4-2,3$ \\
\hline \multicolumn{5}{|l|}{ (Witkowski) E.A Morales* } \\
\hline Rhaphoneis castracanii Grunow & - & - & - & 0,4 \\
\hline Rhopalodia gibba (Ehrenberg) O.Müller var. gibba & - & - & - & + \\
\hline Rhopalodia gibberula (Ehrenberg) O.Müller & + & - & - & - \\
\hline Rhopalodia rumrichiae Krammer & $1,2-2,4$ & - & 0,4 & $0,9-1,2$ \\
\hline Seminavis strigosa (Hustedt) Danielidis \& Economou- & 0,4 & - & 0,4 & $0,4-2,3$ \\
\hline \multicolumn{5}{|l|}{ Amilli } \\
\hline Skeletonema sp. & - & - & - & $0,8-3,8$ \\
\hline Staurophora salina (Wm. Smith) Mereschkowsky & - & - & - & + \\
\hline Staurosira longirostris (Frenguelli) Metzeltin* & - & - & - & 0,4 \\
\hline Staurosira obtusa (Hustedt) M.Garcia & - & - & - & + \\
\hline Staurosirella martyi (Hèribaud-Joseph) E.A.Morales \& & $0,2-1,0$ & - & $0,4-2,7$ & $0,8-2,3$ \\
\hline \multicolumn{5}{|l|}{ K.M.Manoylov } \\
\hline Stephanodiscus hantzschii Grunow & - & - & - & + \\
\hline Surirella litoralis Hustedt* & - & $1,3-4,9$ & - & - \\
\hline Surirella rorata Frenguelli & - & - & - & + \\
\hline Surirella sp. & - & - & - & + \\
\hline Tabularia fasciculata (C.A.Agardh) Williams \& Round & $6,7-8,1$ & - & - & $0,8-1,4$ \\
\hline Tabularia tabulata (C.A.Agardh) Snoeijs & $0,2-0,6$ & $0,4-0,9$ & 0,9 & 0,4 \\
\hline Terpsinoë americana (J.W.Bailey) Gronow & - & - & - & + \\
\hline Terpsinoё musica Ehrenberg & - & - & - & + \\
\hline Thalassiosira eccentrica (Ehrenberg) Cleve & - & - & - & 0,4 \\
\hline Thalassiosira weissflogii (Grunow) Fryxell \& Hasle & 0,2 & - & - & - \\
\hline Triceratium favus Ehrenberg & - & - & + & - \\
\hline Tryblionella acuminata W.Smith & - & - & $0,5-1,4$ & $0,8-1,4$ \\
\hline Tryblionella circunsuta (Bailey) Ralfs & - & - & - & + \\
\hline Tryblionella levidensis W.Smith & 0,2 & - & - & - \\
\hline Tryblionella limicola (Grunow) D.G.Mann* & + & - & - & - \\
\hline Tryblionella salinarum (Grunow) Pantocsek & + & - & - & - \\
\hline Tryblionella victoriae Grunow & + & - & - & - \\
\hline Número total de táxons & 91 & 29 & 47 & 100 \\
\hline
\end{tabular}

